\title{
The gross anatomy of the male reproductive system of the European hedgehog (Erinaceus Europaeus)
}

\author{
G. Akbari, M. Babaei, D. Kianifard, D. Mohebi \\ Department of Basic Sciences, Faculty of Veterinary Medicine, University of Tabriz, Tabriz, Iran \\ [Received: 1 March 2017; Accepted: 30 May 2017]
}

\begin{abstract}
Hedgehogs are small spiny-coated insectivores. Due to their low body weight, calm character, and easy maintenance, they are kept as pets. It is therefore worthwhile to care about hedgehogs' health problems and to provide pet owners with information about their reproduction. Moreover, it is necessary to be familiar with their anatomy so as to satisfy the need to improve nutrition and medical care, even surgery. This study was carried out on five adult male European hedgehogs euthanased in a chloroform chamber. The European hedgehog's oval testes are invisible in inguinal region because they have no true scrotal sac. The testes are located in the craniocaudal direction with dorsolateral epididymal attachments. The vesicular glands, the European hedgehog's largest accessory sex glands, are lobulated structures containing dorsomedial and ventrolateral parts on each side. The prostate is an oval gland with right and left lobes. The paired bulbourethral glands are laid on the ischiocavernosus muscle. Histologically the vesicular, prostate gland ducts and ductus deferens as well as urethra separately were discharged in a diverticlum at the level of the pelvic urethra end. A sigmoid flexure exists in the proximal part of shaft body of the penis. There are two retractor penile muscles. In dorsal end of the penile glans, there is a small urethral process with two nail-like, needle-shaped structures. They are on both sides of the urethral process. Furthermore, there are two intromittent sacs (Sacculus urethralis) in the ventral part of the end of the penis. (Folia Morphol 2018; 77, 1: 36-43)
\end{abstract}

Key words: European hedgehog, male, penis, urethra, accessory sex glands

\section{INTRODUCTION}

In male mammals, the standard reproductive system consists of the testes and relevant epididymis, accessory sex gland complex, ductus deferens, urethra, and penis. The accessory sex gland complex comprises the vesicular gland, ampullary gland, prostate gland, bulbourethral glands, and coagulating glands. Nonetheless, not every mammalian order has all of the glands [17]. Scrupulous attention has always been given to the study of reproductive organs because, it is important to produce basic information on anatomy and histology of male reproductive system since it has considerable significance in breeding, in order to make a pathological diagnosis and provide clinical treatment of diseases [6, 8, 17, 18, 22]. Several studies have been performed on the structure and function of reproductive organs in lots of species. However, little attention has been given to European

Address for correspondence: Dr. G. Akbari, Department of Basic Sciences, Faculty of Veterinary Medicine, University of Tabriz, Tabriz, Iran, tel: +98 (041) 36378743, fax: +98 (041) 36378743, e-mail: g.akbari@tabrizu.ac.ir 
hedgehogs [16]. Undoubtedly, they are indispensable to wildlife conservation.

Hedgehogs are spiny-coated insectivores. They are small and nocturnal creatures. Owing to their low body weight, calm character, and ease of maintenance, hedgehogs could entertain exotic-pet hobbyists. Therefore, it is necessary to be familiar with hedgehogs' health problems and moreover provide pet owners with information about reproduction among hedgehogs.

Naturally, they are found in the British Isles across Europe and in Asia and Africa. The subfamily Erinaceinae comprises three genera and several species. Nonetheless, hedgehogs which could be regarded as popular pets are of two varieties, namely the African hedgehog (Atelerix albiventris) and the larger European hedgehog (Erinaceus europaeus). The European hedgehog is the only species of hedgehogs that are naturally found in England. Hedgehogs have legal protection in both European countries and the United States of America [24].

This study aims to describe the morphology and topography of the male reproductive system of the European hedgehog

\section{MATERIALS AND METHODS}

Five mature male European hedgehogs (weight: $753.4 \pm 33.11 \mathrm{~g}$ ) were used for the present study. They were collected from the suburbs of Tabriz, East Azerbaijan, Iran, in the spring, the beginning of the European hedgehogs reproductive activity season. Their diet consisted of insects and water, which was given ad libitum. All animal procedures employed in this study were approved according to the standards of the University of Tabriz on Human Care and Use of Laboratory Animals by the Research Ethics Committee of the Ministry of Health and Medical Education in Iran (adopted on April 17, 2006), based on the Helsinki Protocol (Helsinki, Finland 1975). Each animal was weighed live, and then sacrificed by an overdose of chloroform in a tightly closed container.

\section{Dissection}

Each animal was opened up, and the reproductive organs were viewed and photographed, in situ. Images of the excised genital organs were taken with a digital camera and therefore the length, width, circumference, and weight of the genital organs were recorded using a ruler, thread, and weighing scale (Shimadzu AW320, Germany). Tissue samples were taken from various parts of the reproductive system.
For histological study all of the slides were stained with haematoxylin and eosin (H\&E), and examined in the light microscope.

\section{RESULTS}

The oval testes of the European hedgehog are intra-abdominal, as there are no true scrotal sacs, but the protrusions of scrotal pouches were in contact with the abdominal muscles in the pubic region. The longitudinal axis of the testes was horizontal and the epididymal border was dorsal, while the free border was ventral. Testes are pinkish brown (Figs. 1, 2). The average length, diameter, and weight of the testes were $1.72 \pm 0.04 \mathrm{~cm}, 1.11 \pm 0.03 \mathrm{~cm}$, and $1.25 \pm$ $\pm 0.05 \mathrm{~g}$, respectively. The mean testicular weight ( $\mathrm{g} \pm \mathrm{SEM}$ ) was $0.17 \pm 0.002 \%$ as a percentage of body weight. Histologically, the testes were covered with a strong stroma called tunica albuginea. The testes normally formed germinal epithelium, which had all cellular stages of the spermatogenesis.

The epididymis was an elongated and convoluted tube strongly attached to the testis dorsolaterally. The epididymal components, namely head, body and tail, were easily identifiable (Figs. 1, 2). The average length $(\mathrm{cm} \pm \mathrm{SEM})$ of the epididymis was $21.97 \pm$ $\pm 0.46 \mathrm{~cm}$. Histologically, the epididymis was lined by pseudostratified columnar epithelium. The ductus deferens arose from the terminal part of the tail of the epididymis. They were pink tubes with thick walls, and entered the urethra. The average length and diameter of the ducts were $3.35 \pm 0.13 \mathrm{~cm}$ and $0.14 \pm 0.01 \mathrm{~cm}$, respectively. There was no enlargement in distal part of ductus deferens at the level of the urinary bladder neck and it was dorsally entered to the dorsal wall of the intrapelvic urethra (Fig. 1).

The accessory glands of the male hedgehog were separately laid closed to the intrapelvic urethra (Figs. 1, 2). The seminal vesicles were located on the dorsal surface of the urinary bladder and ductus deferens. They extended close to the spleen in the abdominal cavity (Fig. 2). This gland included a dorsomedial part and a ventrolateral part but the dorsomedial part was smaller than the ventrolateral part. Each of these glands was attached to the pelvic urethra by means of a long duct (Figs. 1, 3A). The ventral duct was larger than the dorsal one. The average length and diameter of the dorsal duct were $2.21 \pm 0.27 \mathrm{~cm}$ and $0.45 \pm 0.12 \mathrm{~cm}$, respectively. Furthermore, the average length and diameter of the ventral duct were $2.51 \pm 0.42 \mathrm{~cm}$ and $0.54 \pm 0.17 \mathrm{~cm}$, respectively. 


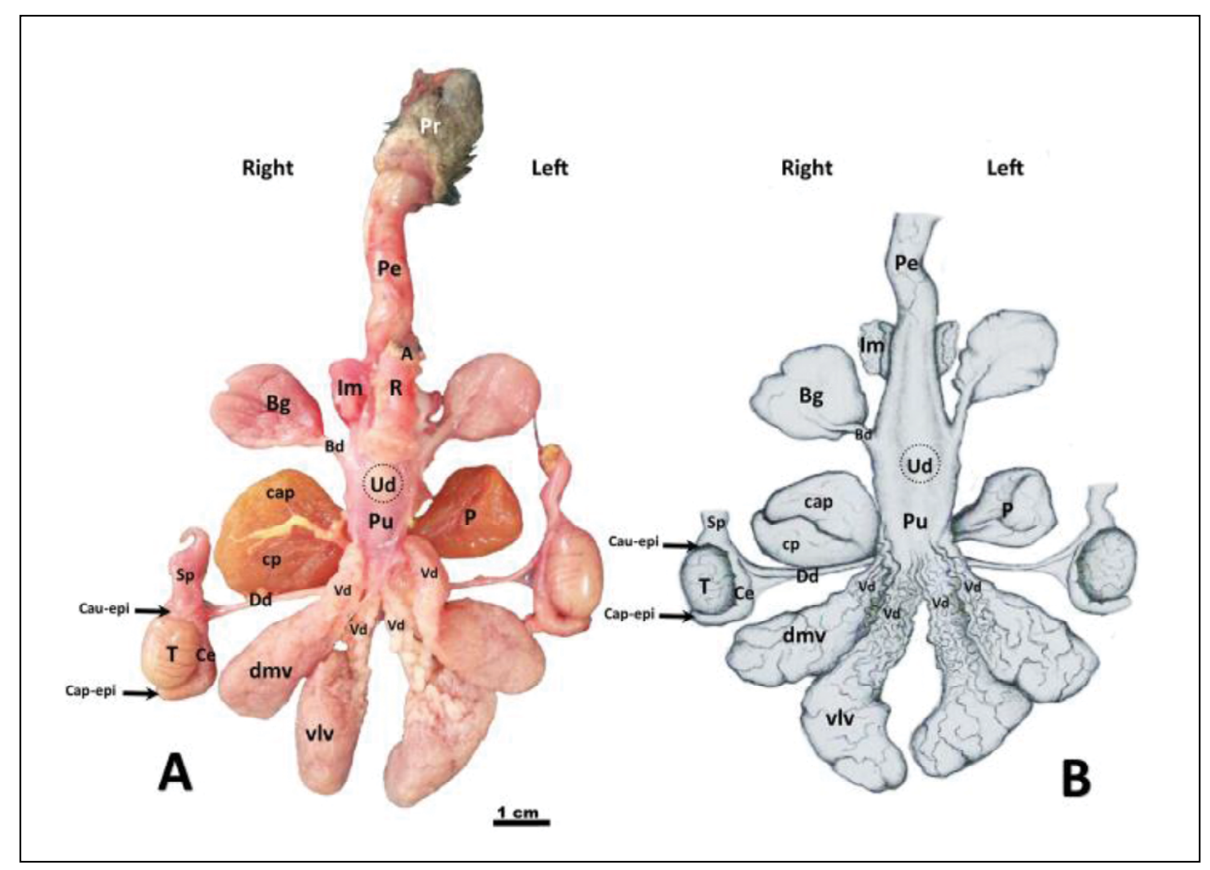

Figure 1. Dorsal view of the reproductive system of a male European hedgehog: $A$ photograph $(\mathbf{A})$ and schematic representation $(\mathbf{B}) ; \operatorname{Pr}-\operatorname{prepuce}$; $\mathrm{Pe}$ — penis; $\mathrm{A}$ - Anus; $\mathrm{R}$ - rectum; $\mathrm{Bd}$ — bulbourethral duct; $\mathrm{Bg}$ — bulbourethral gland; Im — ischiocavernosus muscle; $\mathrm{T}$ — testis; Dd — ductus deferens; Cap-ep — caput epididymidis; Cau-ep — cauda epididymidis; Ce — corpus epididymidis; $\mathrm{Sp}$ — scrotal pouch; P — prostate gland; $\mathrm{CP}$ — cranial part of the right prostate gland; $\mathrm{CaP}$ — caudal part of the right prostate gland; $\mathrm{dmv}$ — dorsomedial lobe of the vesicular gland; vlv — ventrolateral lobe of the vesicular gland; $\mathrm{Vd}$ — vesicular duct; $\mathrm{Ud}$ — urethral diverticulum; $\mathrm{Pu}$ — pelvic urethra.

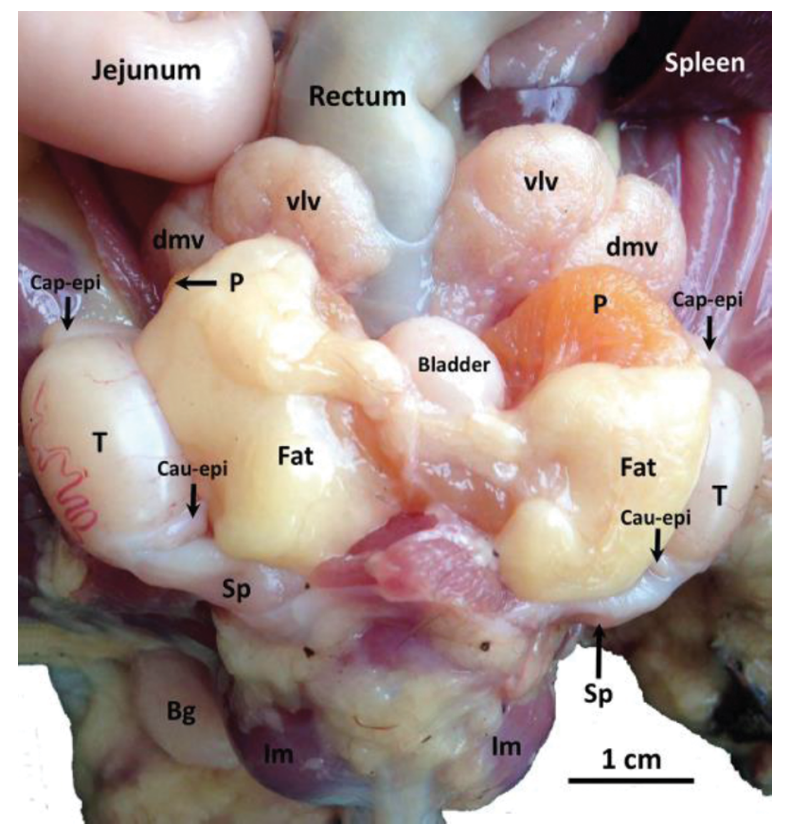

Figure 2. Ventral view of the reproductive system of a male European hedgehog. Topographic position of the organs; $\mathrm{Bg}$ - bulbourethral gland; Im — ischiocavernosus muscle; T — testis; Cap-epi — caput epididymidis; Cau-epi — cauda epididymidis; $\mathrm{Sp}$ - scrotal pouch; $\mathrm{P}$ — prostate gland; $\mathrm{dmv}$ — dorsomedial lobe of the vesicular gland; vlv — ventrolateral lobe of the vesicular gland.
The vesicular glands of the European hedgehog were lobulated structures. Moreover, this gland included dorsomedial leaf-form and ventrolateral sockform glands (Fig. 1). The average length of dorsomedial and ventrolateral vesicular gland was $4.55 \pm$ $\pm 0.31 \mathrm{~cm}$ and $5.16 \pm 0.25 \mathrm{~cm}$, respectively and the average widths of the middle part of the dorsomedial and ventrolateral vesicular glands were $1.41 \pm 0.16 \mathrm{~cm}$ and $1.72 \pm 0.11 \mathrm{~cm}$, respectively. The average diameters of the middle part of the dorsomedial and ventrolateral vesicular glands were $1.27 \pm 0.03 \mathrm{~cm}$ and $1.42 \pm 0.06 \mathrm{~cm}$, respectively. The mean weight of the dorsomedial and ventrolateral vesicular glands were $3.93 \pm 0.04 \mathrm{~g}$ and $4.33 \pm 0.06 \mathrm{~g}$, respectively. The vesicle glands are the largest accessory sex glands in the European hedgehog. They have a pale yellowish-cream colour (Figs. 1, 2).

The prostate gland was a yellow gland with two lobes, one either side (Figs. 1, 2). The right lobe of the prostate in the European hedgehog was larger than the left lobe and was divided into two parts, a caudal part and a cranial part. The cranial part was slightly larger than the caudal part (Fig. 1). These 


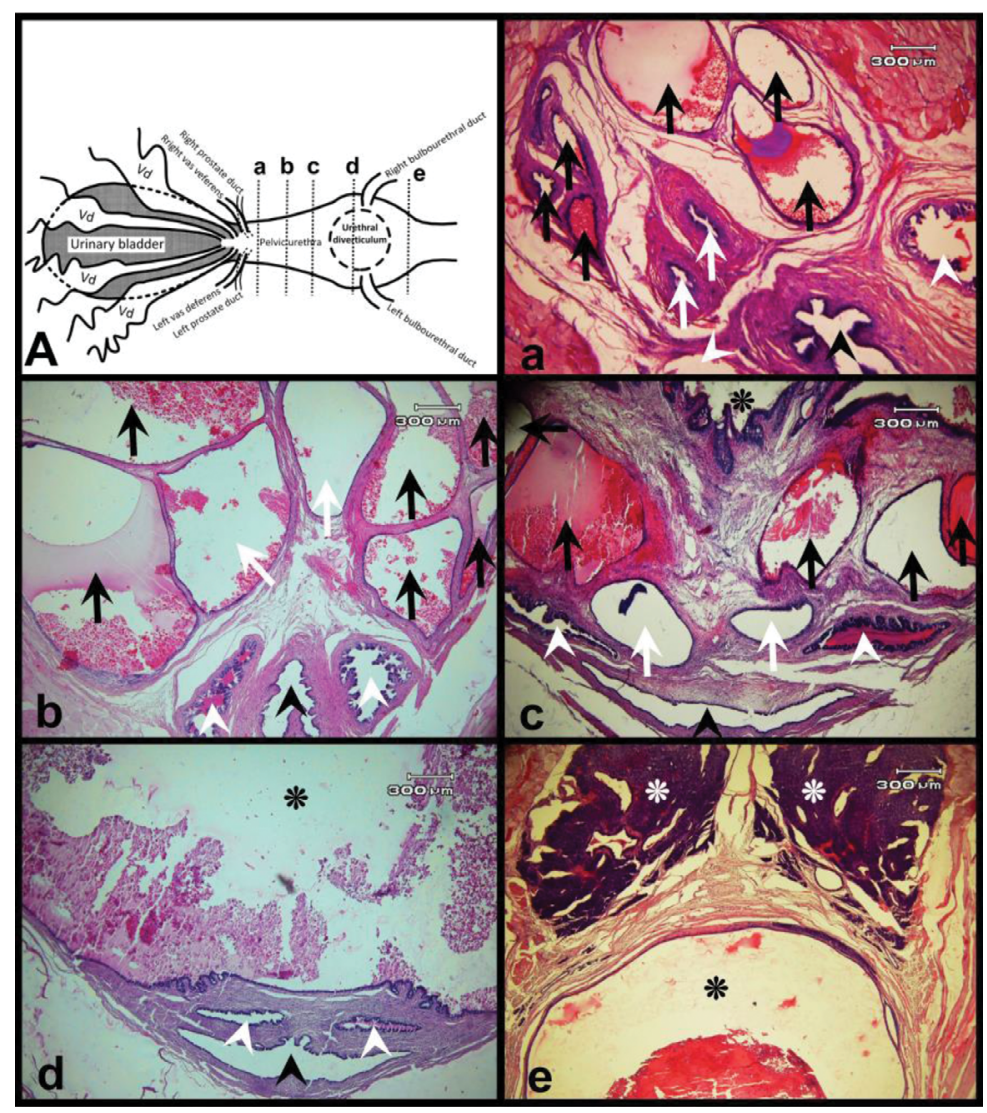

Figure 3. Schematic view of the intrapelvic urethral and ducts of accessory genital glands of a male European hedgehog (A) and its histological cross sections (a-e). Urethra (black arrowhead), prostate duct (white arrowhead), vesicular duct (black arrow) (a-c), vesicular duct (Vd) (A). Ductus deferens (white arrow), urethral diverticulum (black asterisk), urethral gland (white asterisk). Scale bar (a-e): $300 \mu \mathrm{m}$.

glands were located between the testes, and were interposed ventral to the urethra and vesicular glands. In addition, an enormous amount of yellow fat was there between the prostate and the testis (Fig. 2). The ducts of these glands penetrated the urethral muscles ventrolaterally (Fig. 3A). The average number of the prostate lobes on the left was 12; it was 13 on the right. The prostate glands were oval-shaped, resembling a dried apricot. The average length of the left prostate was $2.39 \pm 0.72 \mathrm{~cm}$ while that of the right prostate was $4.69 \mathrm{~cm} \pm 0.97 \mathrm{~cm}$. The average width of the left gland was $1.65 \pm 0.32 \mathrm{~cm}$ and that of the right gland was $2.43 \pm 0.32 \mathrm{~cm}$. Moreover, the average diameter of the left gland was $2.38 \pm$ $\pm 0.29 \mathrm{~cm}$ but in the right gland that was $1.49 \pm$ $\pm 0.23 \mathrm{~cm}$. Furthermore, the mean weight of left and right prostate lobes was $2.54 \pm 0.02 \mathrm{~g}$ and $2.95 \pm$ $\pm 0.02 \mathrm{~g}$, respectively.

The paired bulbourethral glands were located outside the pelvic cavity, on both sides of the anus overlying the ischiocavernosus muscle. They were large, non-lobulated, oval glands (Figs. 1, 2, 4). The ducts of these glands continued craniomedially and entered the dorsolateral part of the distal pelvic urethra (Figs. 1, 3A, 5A). The mean total length, diameter and weight of bulbourethral gland were $1.61 \pm 0.15 \mathrm{~cm}, 0.64 \pm 0.08 \mathrm{~cm}$ and $1.96 \pm 0.04 \mathrm{~g}$, respectively.

The intrapelvic urethra extended between the urinary bladder and penile bulb. At the end of intrapelvic urethra and close to penile bulb there was a large cavity which is called urethral diverticulum (Fig. 1). Moreover, the average diameter of proximal part of intrapelvic urethra was $0.72 \pm 0.05 \mathrm{~mm}$ while the average diameter of its distal part was increased to $12.23 \pm 1.90 \mathrm{~mm}$ in urethral diverticulum (Figs. 1, 3A).

The histological examinations revealed that ductus deferens, vesicular and prostatic ducts, separately from the urethra, penetrate the urethralis muscle and enter this muscle. These ducts were located in the dorsal side of urethra in urethralis muscle and extended caudally close to the penile 


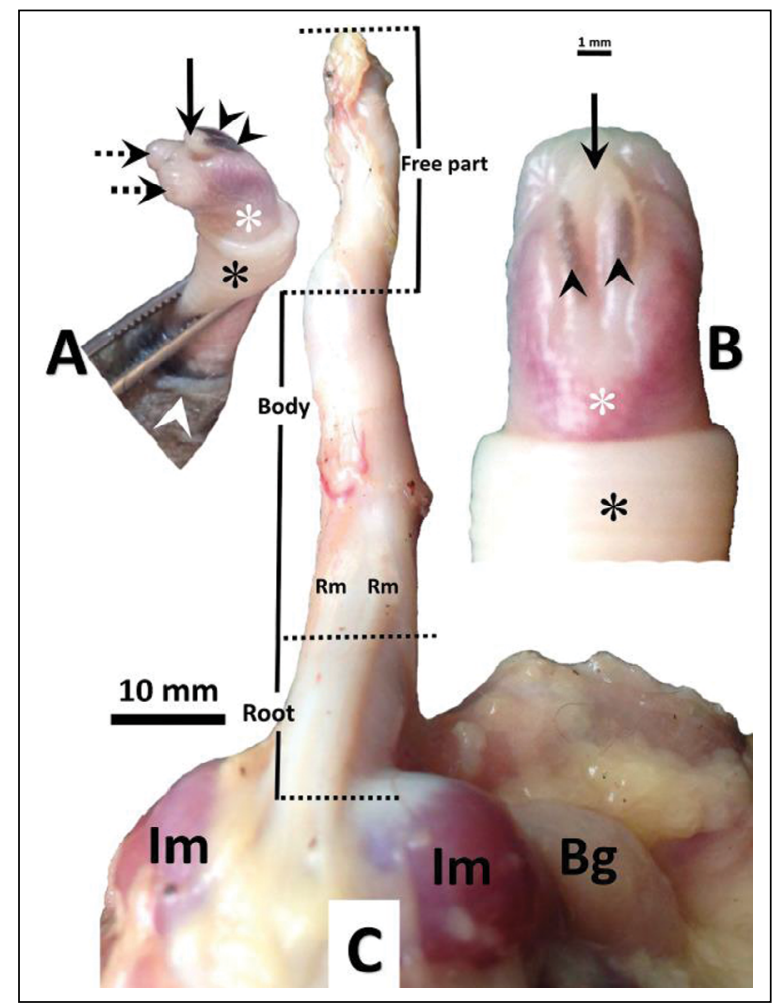

Figure 4. Structure of the penis of a male European hedgehog. A. Ventrolateral view of glans penis. B. Dorsal view of glans penis. C. Dorsal view of penis with root, body and free parts. Glans penis (white asterisk), internal lamina of prepuce (black asterisk), external lamina of prepuce $w$ arrowhead), urethral process (black arrow), penile nail (black arrowhead), sacculus urethralis (black dashed arrow); $\mathrm{Bg}$ - bulbourethral gland; $\mathrm{Im}$ — ischiocavernosus muscle; $\mathrm{Rm}$ — retractor penis muscle.

bulb (Figs. 3a, b, c). Simultaneously, the thickness of the wall of these ducts decreased and at the proximity of the penile bulb they reached urethral diverticulum (Figs. 3b, c). The ductus deferens and the ducts of vesicular glands enter the diverticulum before the prostatic ducts and urethra (Fig. $3 \mathrm{~d}$ ). This urethral diverticulum was a voluminous and globular cavity (Figs. 3c, d, e). Moreover, the urethra was lined with pseudostratified columnar epithelium at the beginning part of urinary bladder (Fig. 3a) but, by approaching to diverticulum, it was changed to nonkeratinised stratified squamous epithelium in urethral diverticulum (Figs. 3e, 5A).

In dorsal part of diverticulum and penile bulb, there were two urethral glands with multiductus tubuloalveolar secretory units with seromucoid secretions. These glands extended from diverticulum to the end of the penile bulb (Figs. 3e, 5A, B).

The penis of the hedgehog attached to the ischiatic arch in the urogenital region, extended subcutaneously and cranially to the umbilical region. This white organ with an average length of $5.46 \pm 0.36 \mathrm{~cm}$ typically had three portions, namely the crura, body, and glans penis. There was a sigmoid flexure in the proximal part of penile shaft body. There were two retractor muscles in the dorsal part of the penis. The muscles extended from penile root to the end of the penile body. The glans penis was red and fully covered with the preputium in a non-erectile condition (Figs. 1, 4C).

In dorsal end of the glans, there was a small urethral process with two nail-like structures. They were on both sides of the urethral process. This nail-like structure bent downward. The end of this structure was black (Figs. 4A, 4B). Histological examinations revealed that these penile nails were a continuation of corpus cavernosum penis and were composed of dense connective tissue with keratinised stratified squamous epithelium (Fig. 5C). In addition, there were two intromittent sacs (Sacculus urethralis) in the ventral part of the end of the penis (Fig. 4C).

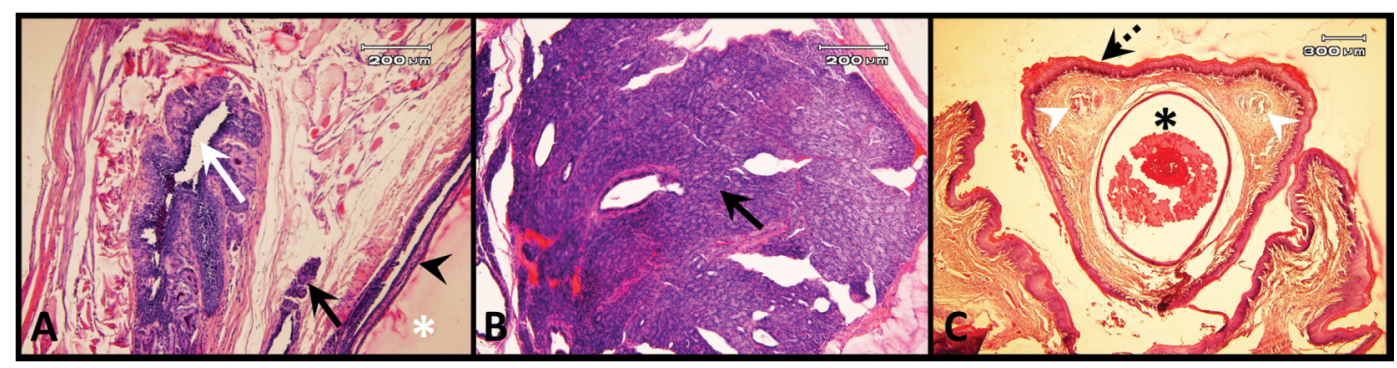

Figure 5. Histological photographs of haematoxylin and eosin $(\mathrm{H} \& \mathrm{E})$ stained sections. Bulbourethral gland duct (white arrow) located dorsolaterally to the urethral diverticulum (white asterisk) which is lined with nonkeratinized stratified squamous epithelium (black arrowhead) (A) and urethral gland (black arrow) is shown at dorsal of urethral diverticulum (A, B). Penile nails (white arrowheads) with keratinised stratified squamous epithelium (black dashed arrow) placed lateral to the urethral process (black asterisk). Scale bar (A, B): $200 \mu \mathrm{m}$; (C): $300 \mu \mathrm{m}$. 


\section{DISCUSSION}

According to Godet's [11] descriptions of the development of the male reproductive system in three families of the order Insectivora, the Talpidae are the most primitive, Soricidae are intermediate, and Erinaceidae are the best developed [11].

Slight dorsoventral orientation of the hedgehog's testes, located caudolaterally in the inguinal region, resembles that of the shrews $[14,25]$. Moreover, there are similarities in the location of the testes in the hedgehog, elephant-shrews [25], eastern mole and star-nose mole [5]. Although the testes of a large number of mammalian species are situated in the scrotum, the hedgehog, as the elephant-shrews [25], eastern mole and star-nose mole [5] has scrotal pouches instead of a true scrotal sac. The fat body between the prostate and the testes could be regarded as a protective mechanism for the regulation of temperature.

The epididymis in the hedgehog has common characteristics with that in most mammals. The hedgehog's ductus deferens is fairly thick and short and, as in shrews [14, 25], lacks an ampulla at the end. In Neurotrichus, ampulla is seemingly a development of the distal end of the ductus deferens. The ampulla of the ductus deferens is a characteristic feature of Soricidae, but none have been found up to the present time in other Talpidae [10].

The accessory sex glands of the European hedgehog namely the seminal vesicles, prostate glands, and bulbourethral glands are similar to these of the greater cane rat [1]. There were no coagulating glands which are formed in the male rat [23], and male guinea pig [22].

The prostate and bulbourethral glands are present in the shrews [14, 25], eastern mole and star-nose mole [5], but only the prostate and vesicular glands have been reported to exist in the capybara.

In most of studied animals such as guinea pigs [22] and rats [23], the vesicular glands consist of two parts, which are mostly tubular and thin. In the present study, it was found that the vesicular gland in the hedgehog was very large, had four parts, extended close to the stomach, and occupied a large portion of the abdominal area. Furthermore, it has been indicated that there are no vesicular glands in the tomcat, shrews [14, 25], eastern mole and starnose mole [5].

The description of the prostate gland in animals shows the presence of various lobes, compared with the human whose prostate gland is a single nonlobulated organ [12]. The right and left lobes of the prostate in the guinea pig [22] are united by an isthmus lying on the dorsal part of the neck of the urinary bladder, and at the junction of the seminal vesicles. These descriptions are similar to the results in this study on the hedgehog, but there are a welldeveloped right lobe and a smaller left lobe, without an isthmus. In this animal, the prostate is located between the testes and below the urethra and vesicular glands.

The prostate gland in Neurotrichus is ventral and lateral to the neck of the bladder and consists mainly of two lateral masses or lobes which are divided externally into finger-like lobules [10]. The prostate gland of Elephantulus myurus consists of five paired glands: ventral, outer and inner anterior dorsal, middle dorsal, and posterior dorsal.

According to Treuting and Dintzis [23], the prostate gland in the rats has four lobes, namely anterior, dorsal, lateral, and ventral. The dorsal and lateral lobes are often identified as the dorsolateral lobe. The bulbourethral glands in the guinea pig [22], rat [23], and agouti [17] are located caudally to the prostate, dorsally to the urethra, and dorsolaterally to the ischiocavernosus muscle. This gland in the Persian squirrel is situated at both sides of the anus [2].

The location of the bulbourethral glands in the hedgehog resembles that in the shrews [14, 25], eastern mole and star-nose mole [5] but the difference is that it extends to the dorsal region of the perineal region. In the spotted paca [7] the duct of the vesicular glands, independent of the ductus deferens, discharges into the beginning of the intrapelvic urethra. However, in the guinea pig [22] and rat [23], the duct of this gland unites with the ductus deferens and discharges into the intrapelvic urethra.

The prostate ducts in the agouti [17] and laboratory rat [13] end in the lateral part of the ejaculatory duct, which opens in the urethra seminal colliculus. The dorsal part of the prostate in the guinea pig [22] ends in the urethra through various ducts but the ventral part ends through one single duct.

The ducts of the bulbourethral glands in the hedgehog continued craniomedially and dorsolaterally, and emptied into the proximal part of the urethral diverticulum, such as those of the shrew [25]. But, these ducts in the greater cane rat have a single excretory duct which is somewhat long and ends in the pelvic urethra near the crus of the penis [1]. The 
two ducts of each gland in the Persian squirrel end in the penile bulb [2].

Godet states that the existence of a prostatic diverticulum is a characteristic that marks the progression. The best development of this diverticulum has been observed in the hedgehog, and the worse one in the mole [11]. The above diverticulum has not been observed in any of investigated shrews so far. Similar diverticula have been reported to exist in the guinea pig, Mus muscidus, Cricetus frumentarius, Macroscelides, and Tupaja [14].

In the hedgehog, the ducts of the prostate and vesicular glands independently move along the urethralis muscle and reach the urethral diverticulum. The ducts of the bulbourethral glands as two separate ducts also discharge into the intrapelvic urethra from both sides in this region. In the mole, the diverticulum is not so well-developed; because of this, the ductus deferens enters the urethra at the point where the diverticulum starts, and the prostatic ducts empty somewhat below, completely beyond the urethral diverticulum [11].

In the hedgehog, from the entrance of the ducts of the bulbourethral glands to the penile bulb itself in the dorsal part, there are two separate compound tubuloalveolar glands. Such a gland, under the name of urethral gland has also been reported to exist in the human [19], and mice [20]. These glands have not been found in the mole and shrews [5, 14, 25].

The penis of the hedgehog is very long and extends to the middle of the abdomen. In this regard, it is similar to that of the shrew [25]. Menezes et al. [17] reported the existence of the two bones which are tapered into needle points (keratinaceous structures) at the ventral part of the glans penis in agouti. Also, these structures were determined in guinea pig [9] and porcupine [4]. But, in the dorsal part of the glans penis of the European hedgehog, the corpus cavernosum becomes thin and divides by trabeculae coming from the tunica albuginea and extends dorsally along the urethra and finally appears as two nail-like, needleshaped structures that were composed of dense connective tissue with keratinised stratified squamous epithelium on both sides of the urethral process. These structures have a central cavity which proves that these nails are the elongation of the corpus cavernosum. These penile nail-like structures bend downward in European hedgehogs as keratinaceous structures in guinea pig [9]. These structures could be regarded as a secondary sexual characteristic. Downward bending of these structures proposes that they possibly play the role of an anchorage for the penis during the penetration into the vagina in copulation and might provide more sexual stimulation [9]. Akbari et al. [3] reported the presence of these structures in the Persian squirrel; however, that is an individual structure and consists of the hyaline cartilage that overextends from the penile tip. Moreover, it lacks the central cavity.

Layne [15] reported that the unique feature of a typical hystrictomorph's penis was dependent on the presence of a blind sac in the glans penis below the urethra, called the Sacculus urethralis, becoming everted from a balloon-like bulge during penile erection. The hedgehog does not belong to the order Hystricomorpha; however, it has the Sacculus urethralis like these animals. In addition, the penis of the hedgehog is similar to that of ruminants in terms of having the urethral process, sigmoid flexure of the body shaft of the penis, and well developed retractor muscles. Furthermore, with these semblances to ruminants, the penis of European hedgehog is classified as intermediate-type penis.

The urethral process has been reported to exist in a genus of elephant shrews. The spiny area of the glans exists in insectivores such as moles and shrews $[21,25]$. However, the hedgehog does not have this spiny area. What is more, like other insectivores, these animals also lack the penile bone and preputial glands.

\section{CONCLUSIONS}

In this study, the reproductive system of the European hedgehog showed some considerable differences from that of certain other insectivores. The urethral diverticulum in the European hedgehog was developed and dorsal end of the penile glans had two nail-like structures with a small urethral process situated between them. Furthermore, seminal vesicles in the European hedgehog were the largest accessory sex glands with four separated portions, as distinct from other insectivores.

\section{Acknowledgements}

We would like to thank Dr. Kianifard and Mr. Sadegi for helping us with the specimen collection.

\section{REFERENCES}

1. Adebayo AO, Akinloye AK, Olukole SG, et al. Gross, histological and ultrastructural features of the bulbourethral gland in the greater cane rat (Thryonomys swinderianus). Anat Histol Embryol. 2015; 44(1): 59-65, doi: 10.1111/ ahe.12108, indexed in Pubmed: 24660943. 
2. Akbari G, Gilanpour H, Adibmoradi M. Anatomy of male squirrel (Sciurus anomalus) reproductive organs. Onl J Vet Res. 2016; $20(7$ ): 453-464.

3. Akbari G, Adibmoradi M, Gilanpour H, et al. Anatomical and histological study of penis in Persian squirrel (Sciurus anomalus ). J Vet Res. 2014; 69(4 ): 401-409.

4. Atalar O, Ceribasi AO. The morphology of the penis in porcupine (Hystrix cristata) . Vet Med (Praha). 2006; 51(2 ): 66-70.

5. Bedford JM, Mock OB, Nagdas SK, et al. Reproductive features of the eastern mole (Scalopus aquaticus) and star-nose mole (Condylura cristata). J Reprod Fertil. 1999; 117(2): 345-353, doi: 10.1530/REP-10-0130, indexed in Pubmed: 10690203.

6. Blottner S, Faber D, Roelants H. Studies on the European hare. 56. Seasonal variation of testicular activity in European brown hare Lepus europaeus. Acta Theriol. 2000; 45: 385-394, doi: 10.4098/at.arch.00-38.

7. Borges EM, Branco É, de Lima AR, et al. Morphology of accessory genital glands of spotted paca (Agouti paca Linnaeus, 1766). Anim Reprod Sci. 2014; 145(1-2): 75-80, doi: 10.1016/j.anireprosci.2013.12.014, indexed in Pubmed: 24461579.

8. Brodowski AK, Jegenow K, Pielowski Z, et al. Seasonal changes in histological - morphometric parameters of testes in the European brown hare. Zeitschrift Jagdwiss. 2001; 47(1): 26-33, doi: 10.1007/bf02242411.

9. Cooper G, Schiller AL. Anotomy of the Guinea Pig. Harvard University Press, Cambridge, MA, 1975.

10. Eadie W. A comparative study of the male accessory genital glands of neurotrichus. J Mammal. 1951; 32(1): 36, doi: 10.2307/1375410.

11. Godet R. Morphogenese comparee des voies genitales males chez les Insectivores Lipotyphla. Ann Sei nat (Zool). 1951; 13: 277-289.

12. Gray H. Anatomy of the human body. Lea and Febiger 1918.

13. Hebel R, Stromberg MV. Anatomy and Embriology of the Laboratory Rat. BioMed Verlag, Wörthesee. 1986.

14. Kowalska-Dyrcz A. A comparative study of the male genital tract in some species of shrews. Acta Theriol. 1966; 11: 71-127, plates 5-12, doi: 10.4098/at.arch.66-4.

15. Layne J. The glans penis and baculum of the rodent dactylomys dactylinus desmarest. Mammalia. 1960; 24(1): 87-92, doi: 10.1515/mamm.1960.24.1.87.
16. Mann T. Male accessory organs of reproduction, and their secretory product: the seminal plasma. In: Mann T (ed.). The biochemistry of semen and of the male reproductive tract. Methuen, London, United Kingdom. 1964: 37-78.

17. Menezes D, Neto AA, Oliveira $M$, et al. Morphology of the male agouti accessory genital glands (Dasyprocta prymnolopha Wagler, 1831). Pesqui Vet Bras. 2010; 30(9): 793-797, doi: 10.1590/s0100$736 \times 2010000900014$.

18. Mollineau W, Adogwa A, Jasper N, et al. The gross anatomy of the male reproductive system of a neotropical rodent: the agouti (Dasyprota leporina). Anat Histol Embryol. 2006; 35(1): 47-52, doi: 10.1111/j.14390264.2005.00656.x, indexed in Pubmed: 16433673.

19. Newman J, Hicks RM. Surface ultrastructure of the epithelia lining the normal human lower urinary tract. Br J Exp Pathol. 1981; 62(3): 232-251, indexed in Pubmed: 7248168.

20. Parr MB, Ren HP, Russell LD, et al. Urethral glands of the male mouse contain secretory component and immunoglobulin A plasma cells and are targets of testosterone. Biol Reprod. 1992; 47(6): 1031-1039, indexed in Pubmed: 1493167.

21. Sinclair AW, Glickman SE, Baskin L, et al. Anatomy of mole external genitalia: Setting the record straight. Anat Rec (Hoboken). 2016; 299(3): 385-399, doi: 10.1002/ar.23309, indexed in Pubmed: 26694958.

22. Stan F. Anatomical Particularities of Male Reproductive System of Guinea Pigs (Cavia porcellus). Bulletin of University of Agricultural Sciences and Veterinary Medicine ClujNapoca. Vet Med. 2015; 72(2): 288-295, doi: 10.15835/ buasvmcn-vm:11410.

23. Treuting PM, Dintzis SM. Comparative Anatomy and Histology: A Mouse and Human Atlas. In: Knoblahgh S, True L (eds. ) . Male Reproductive System. Elsevier Science, Burlington 2011: 285-309.

24. Walker EP. Mammals of the World, vol. 1. Baltimore, Johns Hopkins Press. 1964: 125-133.

25. Woodall P. The male reproductive system and the phylogeny of elephant-shrews (Macroscelidea). Mammal Rev. 1995; 25(1-2): 87-93, doi: 10.1111/j.1365-2907.1995. tb00441.x. 